\title{
Aspirin for primary prevention of cardiovascular disease: a meta-analysis with a particular focus on subgroups
}

Georg Gelbenegger ${ }^{1} \mathbb{D}$, Marek Postula ${ }^{2}$, Ladislav Pecen ${ }^{3}$, Sigrun Halvorsen ${ }^{4}$, Maciej Lesiak $^{5}$, Christian Schoergenhofer ${ }^{1}$, Bernd Jilma', Christian Hengstenberg ${ }^{6}$ and Jolanta M. Siller-Matula ${ }^{6 *}$

\begin{abstract}
Background: The role of aspirin in primary prevention of cardiovascular disease (CVD) remains unclear. We aimed to investigate the benefit-risk ratio of aspirin for primary prevention of CVD with a particular focus on subgroups.

Methods: Randomized controlled trials comparing the effects of aspirin for primary prevention of CVD versus control and including at least 1000 patients were eligible for this meta-analysis. The primary efficacy outcome was all-cause mortality. Secondary outcomes included cardiovascular mortality, major adverse cardiovascular events (MACE), myocardial infarction, ischemic stroke, and net clinical benefit. The primary safety outcome was major bleeding. Subgroup analyses involving sex, concomitant statin treatment, diabetes, and smoking were performed.

Results: Thirteen randomized controlled trials comprising 164,225 patients were included. The risk of all-cause and cardiovascular mortality was similar for aspirin and control groups (RR 0.98; 95\% Cl, 0.93-1.02; RR 0.99; 95\% Cl, 0.901.08; respectively). Aspirin reduced the relative risk (RRR) of major adverse cardiovascular events (MACE) by $9 \%$ (RR $0.91 ; 95 \% \mathrm{Cl}, 0.86-0.95)$, myocardial infarction by $14 \%$ (RR 0.86; $95 \% \mathrm{Cl}, 0.77-0.95)$, and ischemic stroke by $10 \%$ (RR $0.90 ; 95 \% \mathrm{Cl}, 0.82-0.99$ ), but was associated with a $46 \%$ relative risk increase of major bleeding events (RR 1.46; $95 \%$ $\mathrm{Cl}, 1.30-1.64)$ compared with controls. Aspirin use did not translate into a net clinical benefit adjusted for eventassociated mortality risk (mean $0.034 \% ; 95 \% \mathrm{Cl},-0.18$ to $0.25 \%$ ). There was an interaction for aspirin effect in three patient subgroups: (i) in patients under statin treatment, aspirin was associated with a 12\% RRR of MACE (RR 0.88; 95\% Cl, 0.80-0.96), and this effect was lacking in the no-statin group; (ii) in non-smokers, aspirin was associated with a 10\% RRR of MACE (RR 0.90; 95\% Cl, 0.82-0.99), and this effect was not present in smokers; and (iii) in males, aspirin use resulted in a 11\% RRR of MACE (RR 0.89; $95 \% \mathrm{Cl}, 0.83-0.95$ ), with a non-significant effect in females.
\end{abstract}

Conclusions: Aspirin use does not reduce all-cause or cardiovascular mortality and results in an insufficient benefitrisk ratio for CVD primary prevention. Non-smokers, patients treated with statins, and males had the greatest risk reduction of MACE across subgroups.

Systematic review registration: PROSPERO CRD42019118474.

Keywords: Primary prevention, Aspirin, Cardiovascular disease, Major adverse cardiovascular event, Myocardial infarction, Stroke, Major bleeding, Cancer, Meta-analysis

\footnotetext{
* Correspondence: Jolanta.siller-matula@meduniwien.ac.at

${ }^{6}$ Division of Cardiology, Department of Internal Medicine II, Medical

University of Vienna, Währinger Gürtel 18-20, 1090 Vienna, Austria

Full list of author information is available at the end of the article
}

C The Author(s). 2019 Open Access This article is distributed under the terms of the Creative Commons Attribution 4.0 International License (http://creativecommons.org/licenses/by/4.0/), which permits unrestricted use, distribution, and reproduction in any medium, provided you give appropriate credit to the original author(s) and the source, provide a link to the Creative Commons license, and indicate if changes were made. The Creative Commons Public Domain Dedication waiver (http://creativecommons.org/publicdomain/zero/1.0/) applies to the data made available in this article, unless otherwise stated. 


\section{Background}

Acetylsalicylic acid (commonly referred to as "aspirin") is an antithrombotic agent that inhibits platelets by irreversibly acetylating the serine residue of cyclooxygenase$1(\mathrm{COX}-1)$ in platelets with subsequently reduced levels of prothrombotic thromboxane $\mathrm{A}_{2}\left(\mathrm{TxA}_{2}\right)$ [1-3]. In patients with known cardiovascular disease (CVD), the potential for aspirin to reduce further cardiovascular (CV) events significantly outweighs the risks of major bleeding and thus aspirin has since become a mainstay in secondary prevention of CVD [4-8]. However, in primary prevention, its role is still under debate [9]. This is due to an as yet unclear balance between the benefits and risks of aspirin treatment in patients without a diagnosed atherosclerotic disease.

Previously published meta-analyses have indicated that aspirin significantly reduced myocardial infarction (MI) and major adverse cardiovascular events (MACE) without an impact on stroke and CV- or all-cause death [10-14]. Furthermore, an increased risk of major bleeding events under aspirin strongly outweighed the benefits of aspirin treatment in primary prevention $[10,12-14]$. As a result, the current guidelines on CVD prevention from the European Society of Cardiology (ESC) do not recommend antiplatelet therapy in patients free of overt CVD [8]. On the contrary, the recently published 2019 ACC/AHA guideline on the primary prevention of cardiovascular disease states that aspirin might be considered in selected adults aged 40 to 70 who are at higher $\mathrm{CV}$ risk but at no increased bleeding risk [15]. The U.S. Preventive Services Task Force recommends initiation of aspirin treatment depending on age and 10year CVD risk [16].

Recently, three major trials (ARRIVE, ASCEND, and ASPREE) evaluating the use of aspirin in primary prevention of CVD were published [17-19]. The ARRIVE trial enrolled patients with moderate to high cardiovascular risk, the ASCEND trial patients with diabetes mellitus (DM) only, and the ASPREE trial elderly patients. Only the ASCEND trial [18] showed a significant reduction in the rate of major adverse CV events, but the effect was, once again, accompanied by a significant increase in major bleeding. Using the three recently published trials, we aimed to perform a meta-analysis with a particular focus on subgroups in order to potentially characterize patient populations with a more favorable benefit-risk ratio.

\section{Methods}

\section{Protocol and registration, data extraction, and quality assessment}

Our review was registered with PROSPERO under the registration number CRD42019118474. Two reviewers applied the selection criteria (GG and JMSM) independently and in duplicate. This study was conducted in accordance with Preferred Reporting Items for Systematic
Reviews and Meta-Analyses (PRISMA) guidelines, as described previously [20-24].

\section{Data sources and searches}

We searched PubMed and Web of Science using predefined search terms (primary prevention AND aspirin AND clinical trial OR meta-analysis) until November 2018. Six additional trials [25-30] that were included in a previous meta-analysis [5] were also identified and included in our analysis. The titles and abstracts of suspected relevant citations were screened for eligibility, and the full text was acquired for further evaluation if the citation was deemed pertinent. References of retrieved meta-analyses and reviews were also checked for additional trials.

\section{Study selection and outcomes}

Included studies had to be randomized controlled trials (RCT) and include at least 1000 patients. Studies had to be controlled (placebo or control group), but could be open-label or blinded. The target patient population comprised patients without any history of CVD. Patients with a low ankle-brachial index (ABI) who had no symptoms and no diagnosis of peripheral arterial disease were considered as a primary prevention cohort. Exclusion criteria were non-RCTs, duplicate reports, ongoing studies, and studies that included patients with history of CVD.

The primary efficacy outcome was all-cause mortality. Secondary efficacy outcomes included cardiovascular mortality, the composite of major adverse cardiovascular events (MACE), MI, and ischemic stroke (IS). MACE was defined as a composite of nonfatal stroke, nonfatal MI, and CV mortality. In order to accurately assess the rate of MACE, we performed two analyses, one comparing the calculated rate of MACE as per our definition and one comparing the rate of the study defined primary outcome as a part of a sensitivity analysis. Stroke was defined as "ischemic stroke" but not all included studies reported on the incidence of IS alone. If not sufficiently specified, the number of reported strokes was used. We also reported on the incidence of hemorrhagic stroke. Bearing in mind the uncertain effect of aspirin on cancer outcomes, cancer risk was prespecified as an exploratory outcome. For further analysis of data, we performed four subgroup analyses involving diabetes, sex, concomitant statin treatment, and smoking.

Major bleeding was the primary safety endpoint. Definition of major bleeding varied between studies. If not defined as "major bleeding," we used the following definitions: "bleeding requiring transfusion," "bleeding rendering patients intensive care dependent," "bleeding causing death," or "intracranial bleeding." The extracranial major bleeding analysis comprised the total of all 
major bleedings and some GI bleeding events that were classified as relevant in respect to the analysis. Intracranial hemorrhages and GI bleedings were also assessed as single endpoints.

\section{Data synthesis and analysis}

Variables are reported as numbers or percentages as appropriate. Risk ratios (RR) were calculated from individual studies and pooled according to the inverse variance model with 95\% confidence intervals (95\% CI) and reported as relative risk reduction or increase respectively (RRR/RRI) within a mean time frame of 6.4 years (which is the mean follow-up period of included studies). The statistical inconsistency test $\left(I^{2}\right)$ was used to assess heterogeneity vs. homogeneity between studies. If the $I^{2}$ value was low $\left(I^{2}<50 \%\right)$, a fixed-effect model was additionally calculated, as reported previously [20, 22, 24]. The following sensitivity analyses were performed: (i) comparison of the results of the fixed vs. random-effect model, (ii) the influence of each study was assessed by testing whether deleting each in turn would have significantly changed the pooled results of the meta-analysis, (iii) sensitivity analysis of the date of publication before and after 2010, (iv) sensitivity analysis assessing the length of follow-up ( $<5$ vs. $>5$ years), and (v) and analysis focusing on the study defined primary outcome parameter.

Absolute risk reduction or increase (ARR, ARI) and number needed to treat or harm (NNT, NNH) were calculated per 1 year of treatment. This was performed as follows: event incidence rates were divided by their respective mean follow-up periods and multiplied by 100 to obtain the incidence rate per 100 patient years. Out of these, the ARR or ARI were calculated by subtraction, and subsequently, the $\mathrm{NNT}$ or $\mathrm{NNH}$ were calculated according to the following formula: NNT or $\mathrm{NNH}=1$ / (ARR or ARI). Events prevented/caused per 10,000 patients per year were calculated by dividing 10,000 by the NNT or NNH. This transformation of data allows for a better understanding of risks for doctors and patients.

The mortality-adjusted net clinical benefit was calculated as follows: [IR $\mathrm{Ischemi}_{\text {stroke_aspirin }}+\mathrm{W} 1 \mathrm{I} \mathrm{R}_{\text {myocardial }}$ infarction_aspirin $+\mathrm{w} 2 \mathrm{IR}_{\text {hemorrhagic }}$ stroke_aspirin $+\mathrm{w} 3 \mathrm{IR}_{\text {major }}$ extracranial bleeding_aspirin $]-\left[\mathrm{IR}_{\text {ischemic }}\right.$ stroke_control + w1IR $R_{\text {myocardial }}$ infarction_control $+\mathrm{w} 2 \mathrm{IR}_{\text {hemorrhagic }}$ stroke_con-

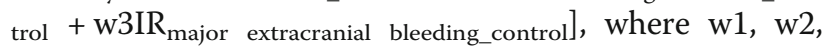
and w3 are the death-related weights associated with each type of event. Weights were calculated as the impact of each event on mortality, as derived from recent analyses [31, 32], and related to IS (weight $=1$ ). Weights were thus $\mathrm{w} 1=0.89$ for MI, w2 $=3.23$ for hemorrhagic stroke, and $\mathrm{w} 3=0.63$ for major extracranial bleeding [31, 32]. In the mortality-adjusted net clinical benefit analysis, a lower estimate indicates a greater benefit of aspirin.
A two-tailed $p$ value of $<0.05$ was considered significant. Review Manager (Version 5.3. Copenhagen: The Nordic Cochrane Centre, The Cochrane Collaboration, 2014) was used for statistical calculations.

\section{Results}

\section{Description of studies}

Our search retrieved 608 references. Five hundred ninety items were excluded based on title and abstracts that were not RCTs, investigated aspirin in secondary prevention of CVD, or were identified as non-pertinent studies (Additional file 1: Figure S1). Additionally, retrieved reviews and meta-analyses were thoroughly examined to identify further trials. One study was excluded as it contained a significant number of patients with definite or suspected CVD [33]. Thirteen trials [17-19, 25-30, 34-37] were eligible for analysis and comprised a total of 164,225 patients, 82,900 allocated to aspirin and 81,325 allocated to the control group. One included study [36] was a 10-year follow-up of a previously published trial [38]. The mean age of patients included in our meta-analysis was 62 years. The mean follow-up period was 6.4 years (ranged from 3.6 to 10.3 years). Three trials exclusively included patients with known diabetes [18, 36, 37]. Three trials included men only $[25,28,30]$, and one trial included women only [29]. The dosage of aspirin ranged from 75 to $500 \mathrm{mg}$ once daily. Two trials evaluated the effect of aspirin $(325 \mathrm{mg}$ and 100 $\mathrm{mg}$ ) given on alternate days $[29,30]$. Only two studies reported the use of proton-pump inhibitors (PPIs) [18, 19]. Included studies are characterized in Tables 1 and 2.

\section{Efficacy and safety outcomes}

All trials reported on all-cause mortality [17-19, 2530, 34-37] and included 164,225 patients. The incidence of all-cause mortality was similar between the aspirin and control groups $(4.52 \%$ vs. $4.54 \%$, respectively; RR 0.98; 95\% CI, 0.93-1.02; $p=0.26 ; I^{2}=0 \%$; Fig. 1, Table 3, Additional file 1: Figure S2A). Use of aspirin was not associated with a reduction in $\mathrm{CV}$ mortality (RR 0.99; 95\% CI, 0.90-1.08; $p=0.75 ; I^{2}=0 \%$; Fig. 1 , Table 3; Additional file 1: Figure S3A) compared with no aspirin. Aspirin was associated with a RRR of MACE by $9 \%$ (RR 0.91; 95\% CI, 0.86-0.95; $p<0.0001 ; I^{2}=0 \%$; ARR 0.052\%; NNT 1908; Fig. 1, Additional file 1: Figure S2B), of MI by $14 \%$ (RR $0.86 ; 95 \%$ CI, $0.77-0.95 ; p=0.005 ; I^{2}=$ 50\%; ARR 0.041\%; NNT 2452; Fig. 1, Table 3, Additional file 1: Figure S3B), and of IS by $10 \%$ (RR 0.90; $95 \%$ CI, 0.82-0.99; $p=0.03 ; I^{2}=17 \%$; ARR 0.022\%; NNT 4448; Fig. 1, Table 3, Additional file 1: Figure S3C) compared with no aspirin.

Twelve studies, including a total of 159,086 patients, reported on the rate of major bleeding complications [17-19, 25-27, 29, 30, 34-37]. Aspirin use was associated with a $46 \%$ RRI of major bleeding complications 


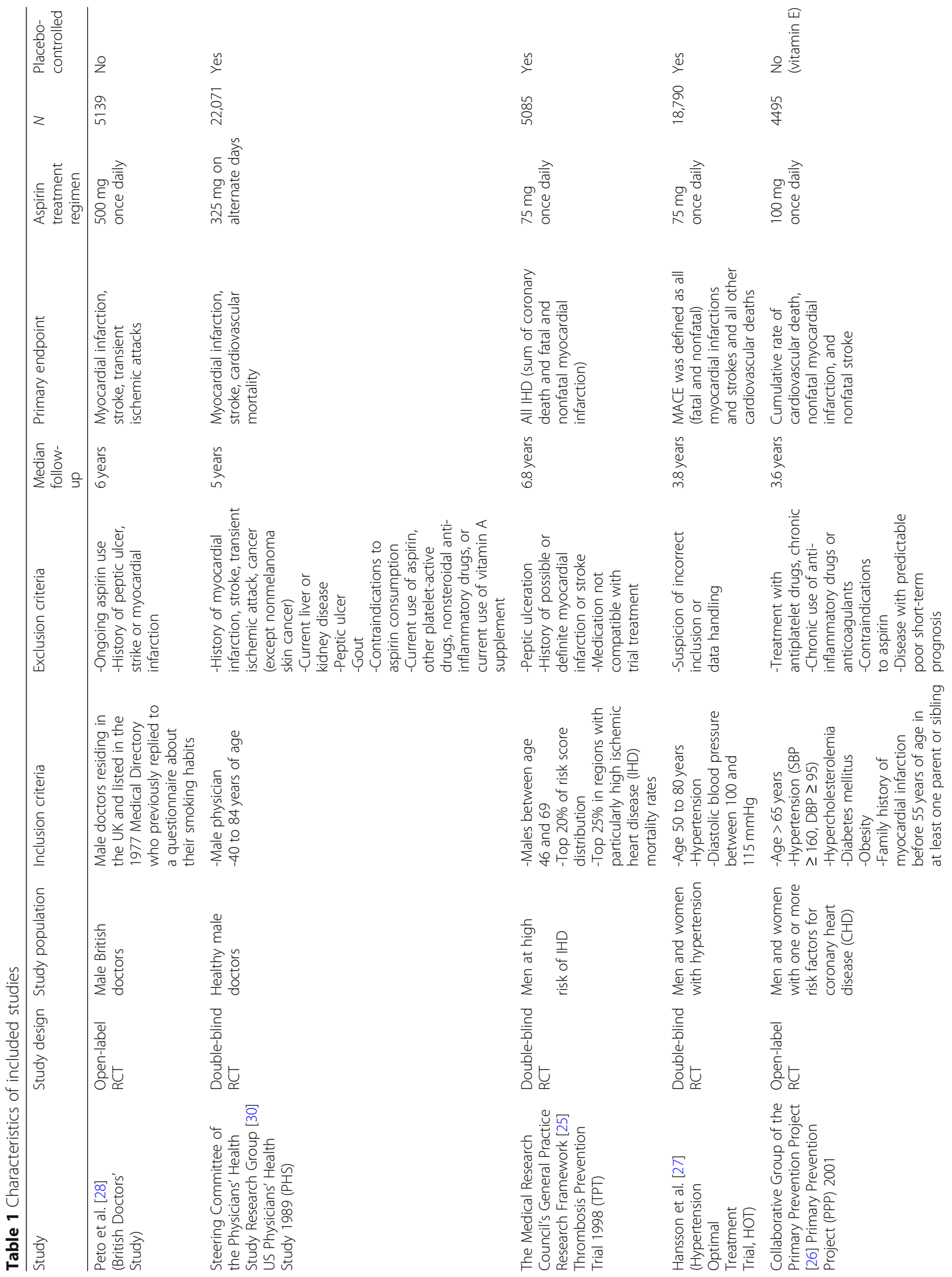




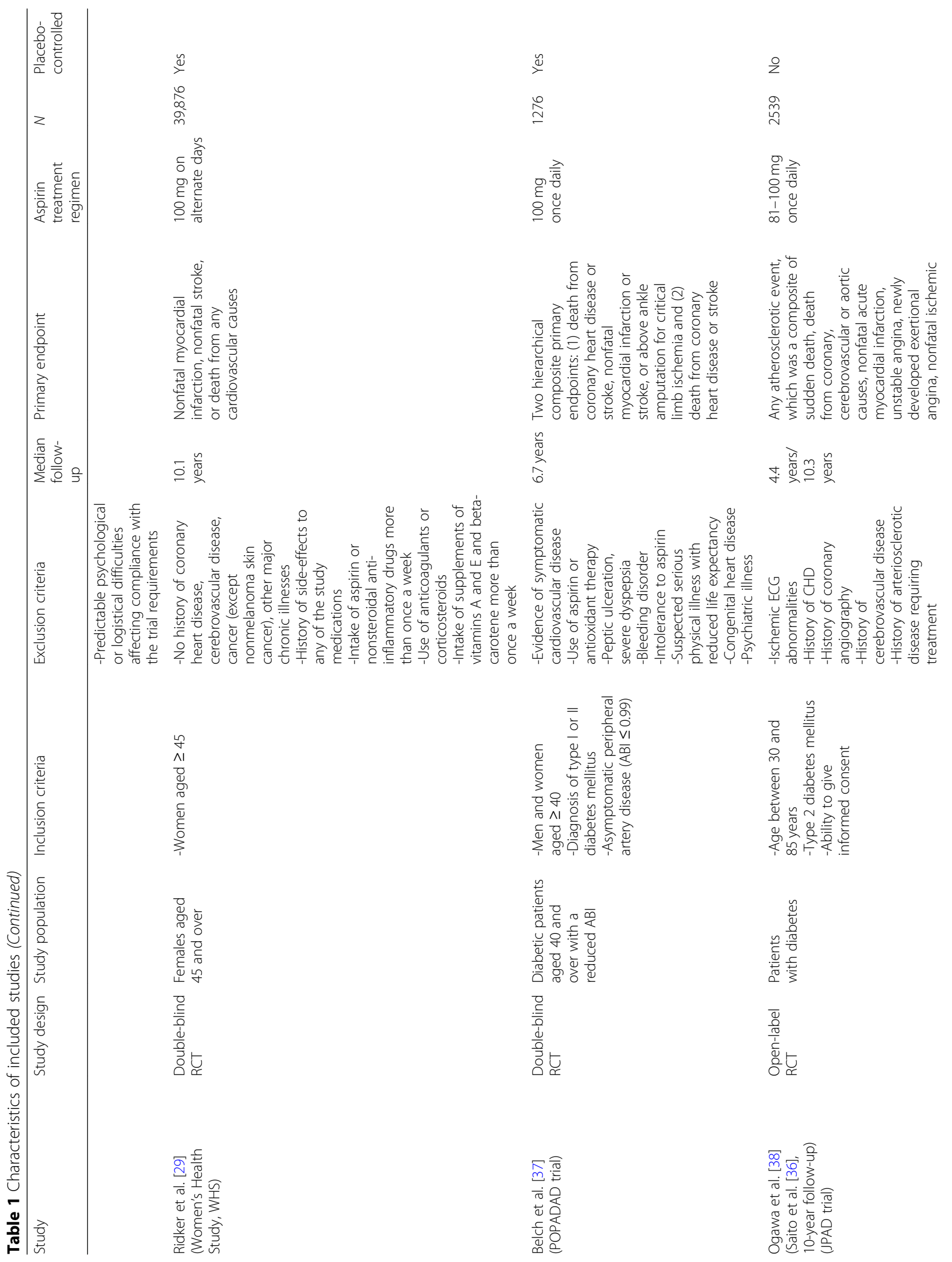




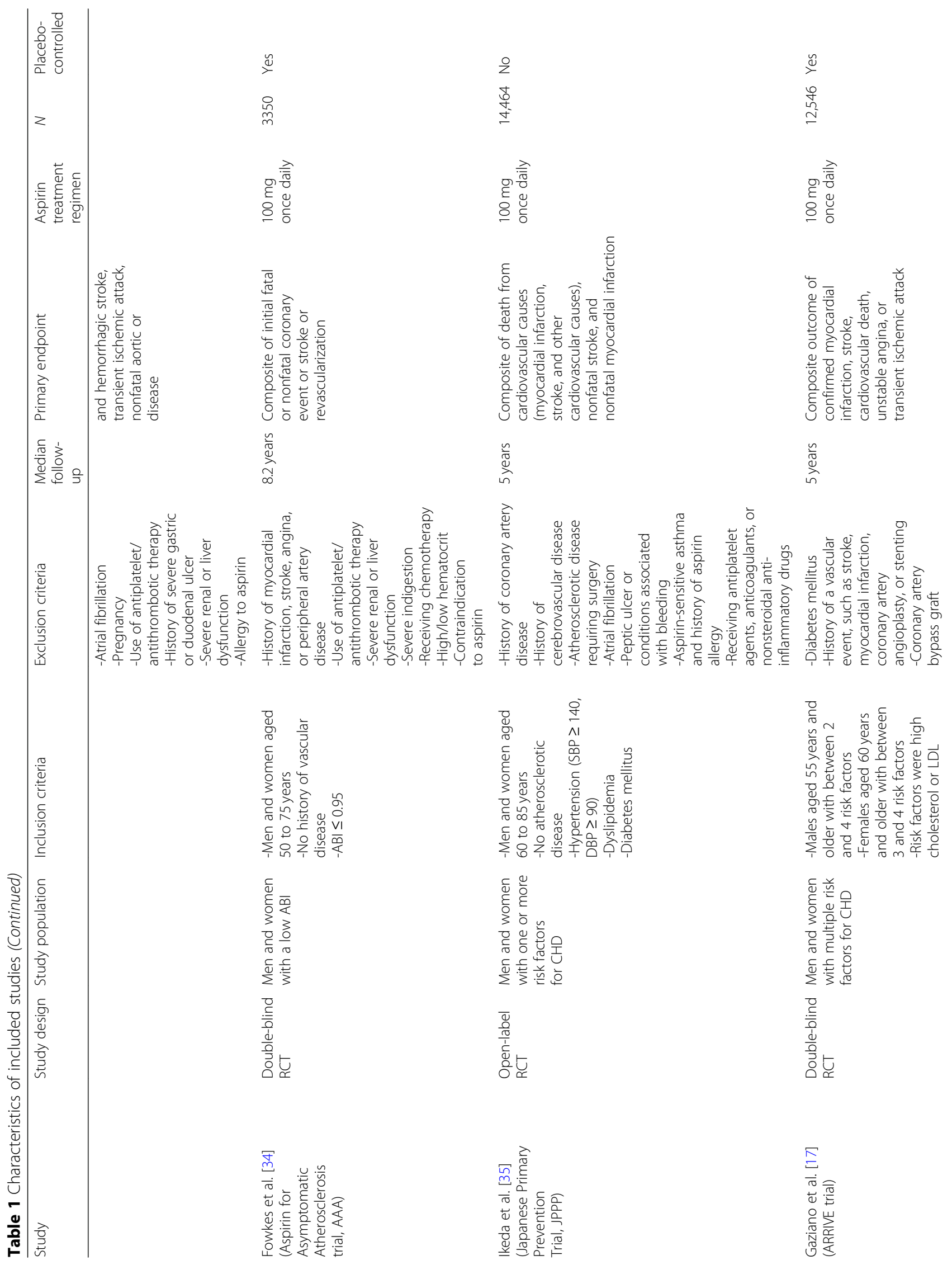




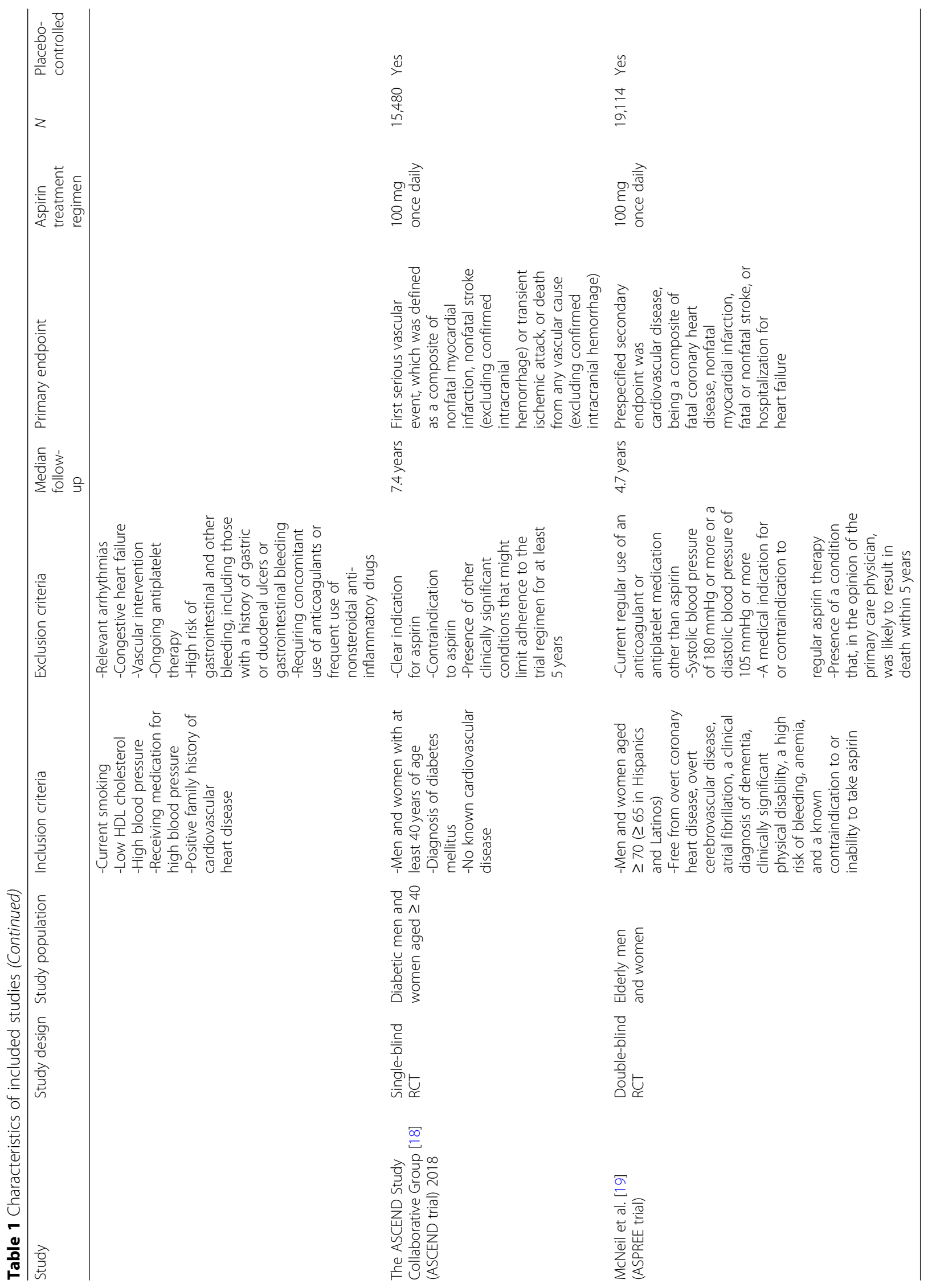




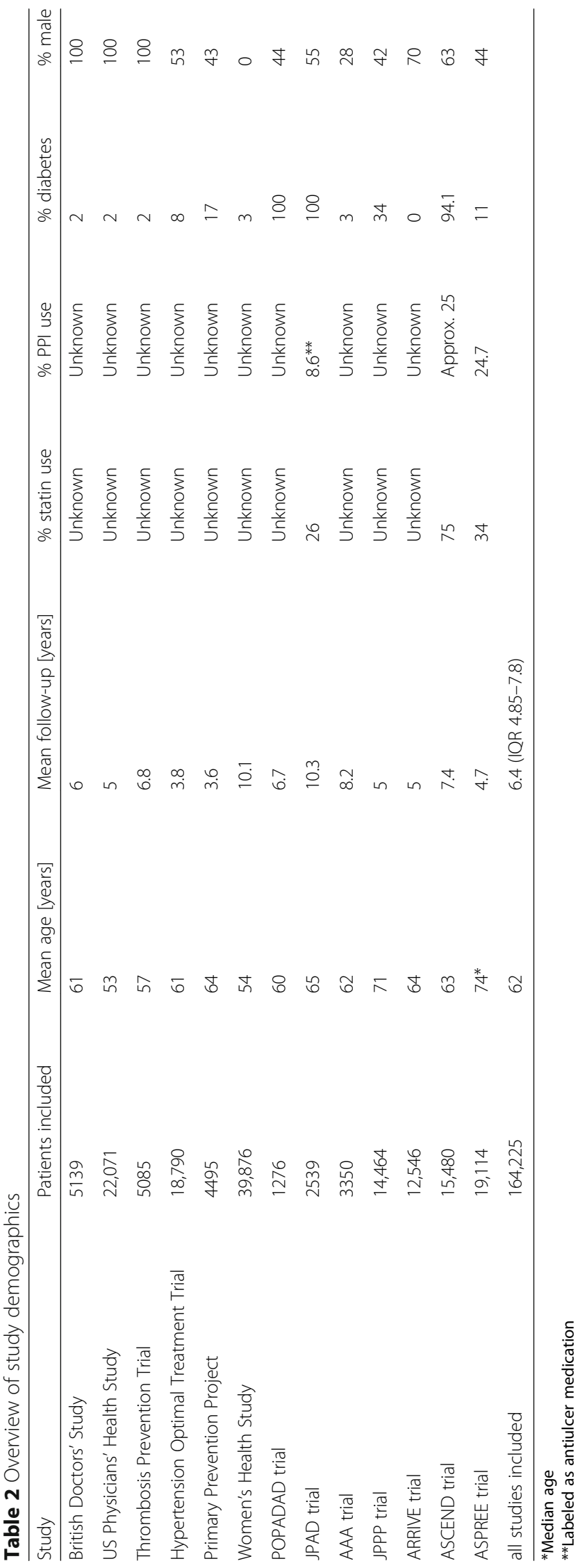




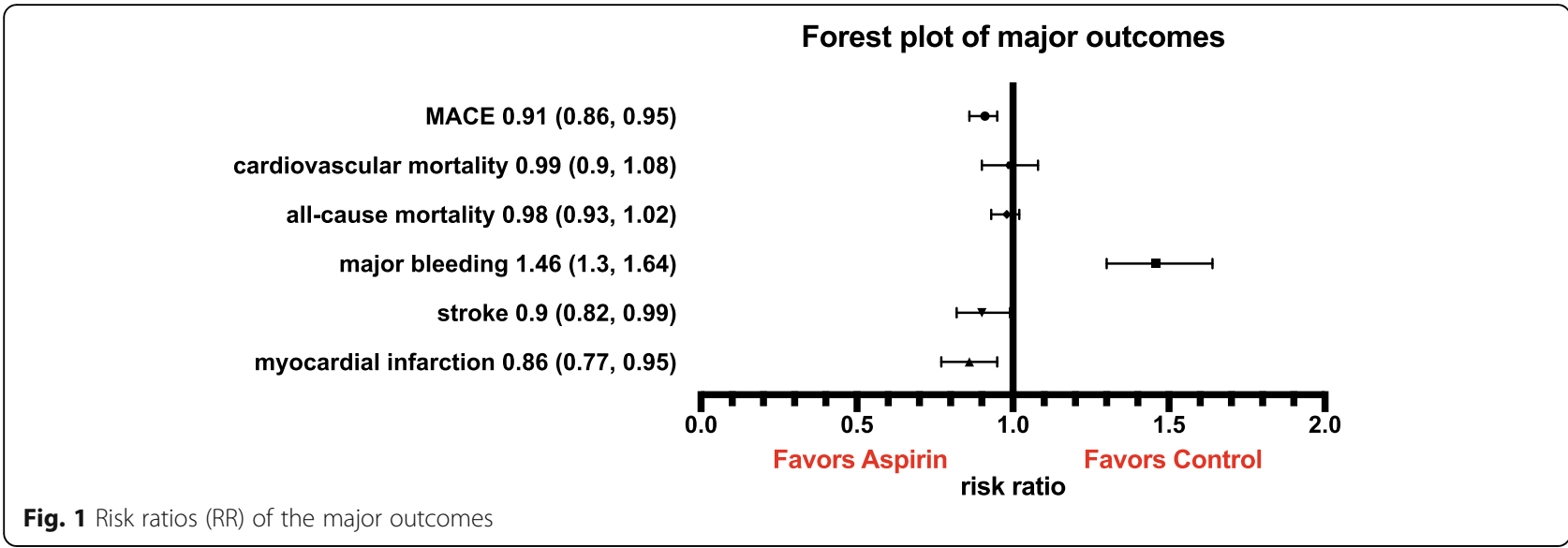

(RR 1.46; 95\% CI, 1.30-1.64; $p<0.00001 ; I^{2}=31 \%$; ARI 0.077\%; NNH 1295; Fig. 1, Table 3, Additional file 1: Figure S2C) compared with no aspirin. Extracranial major bleedings and GI bleedings were the major driver of the composite of bleeding events, with intracranial bleedings and hemorrhagic stroke having no statistical impact (Additional file 1: Figure S4). Aspirin did not decrease the cancer incidence (Additional file 1: Figure S5).

\section{The net clinical benefit}

All trials [17-19, 25-30, 34-37] provided data for the estimation of the adjusted net clinical benefit. Aspirin was not associated with a net clinical benefit after adjustment for event-associated mortality risk (mean $0.034 \%$; $95 \%$ CI, -0.184 to $0.252 \%$; Fig. 2).

The crude net clinical benefit comprising MACE and major bleeding events was calculated with data from 12 studies [17-19, 25-27, 29, 30, 34-37], showing that aspirin did not lead to a net clinical benefit (RR 1.01; 95\% CI, 0.97-1.05; $p=0.54 ; I^{2}=0 \%$; Additional file 1: Figure S6).

\section{Analysis of subgroups \\ Statin treatment}

MACE: Two trials, comprising a total of 34,594 patients, reported on the MACE risk in patients with and without statin treatment $[18,19]$. Aspirin-treated patients who were also treated with statins had a $12 \%$ RRR of MACE when compared with control plus statin (RR 0.88; 95\% CI, $0.80-0.96 ; p=0.007 ; I^{2}=0 \%$; Fig. 3 ). In contrast, aspirin without statin co-treatment did not reduce MACE risk when compared with control without statin (RR 0.94; 95\% CI, 0.83-1.08; $p=0.39 ; I^{2}=25 \%$; Fig. 3).

\section{Smoking}

MACE: Five trials, comprising a total of 88,539 patients, reported on incidence of MACE in smokers and nonsmokers [17, 19, 29, 35, 36]. In non-smokers, aspirin use was associated with a 10\% RRR of MACE (RR 0.90; 95\% CI, $0.82-0.99 ; p=0.04 ; I^{2}=23 \%$; Fig. 4) compared with no aspirin. In smokers, aspirin did not affect the risk of MACE (RR 1.11; 95\% CI, 0.96-1.28; $p=0.16 ; I^{2}=0 \%$; Fig. 4).

Table 3 Risk estimates: absolute risk reduction (ARR) or increase (ARI) and number needed to treat (NNT) or to harm (NNH) for the primary and secondary endpoints over a treatment period of 1 year, which were statistically different between groups

\begin{tabular}{|c|c|c|c|c|c|c|c|c|c|}
\hline Event & $\begin{array}{l}\text { Events per } 100 \text { patient } \\
\text { years in the } \\
\text { aspirin group }\end{array}$ & $\begin{array}{l}\text { Events per } 100 \text { patient } \\
\text { years in the } \\
\text { control group }\end{array}$ & $\begin{array}{l}\text { ARR } \\
\%\end{array}$ & $\begin{array}{l}\text { ARI } \\
\%\end{array}$ & NNT & $\mathrm{NNH}$ & $\begin{array}{l}\text { Events prevented } \\
\text { per } 10,000 \text { treated } \\
\text { patients }\end{array}$ & $\begin{array}{l}\text { Events caused } \\
\text { per } 10,000 \text { treated } \\
\text { patients }\end{array}$ & $p$ value \\
\hline Myocardial infarction & 0.260 & 0.301 & 0.041 & & 2452 & & 4 & & 0.005 \\
\hline Ischemic stroke & 0.218 & 0.240 & 0.022 & & 4448 & & 2 & & 0.03 \\
\hline MACE & 0.613 & 0.665 & 0.052 & & 1908 & & 5 & & $<0.0001$ \\
\hline Major bleeding & 0.257 & 0.180 & & 0.077 & & 1295 & & 8 & $<0.0000$ \\
\hline $\begin{array}{l}\text { Extracranial major } \\
\text { bleeding }\end{array}$ & 0.286 & 0.218 & & 0.068 & & 1462 & & 7 & $<0.0000$ \\
\hline Gl bleeding & 0.399 & 0.320 & & 0.079 & & 1263 & & 8 & $<0.0001$ \\
\hline
\end{tabular}




\section{MORTALITY-ADJUSTED NET CLINICAL BENEFIT}

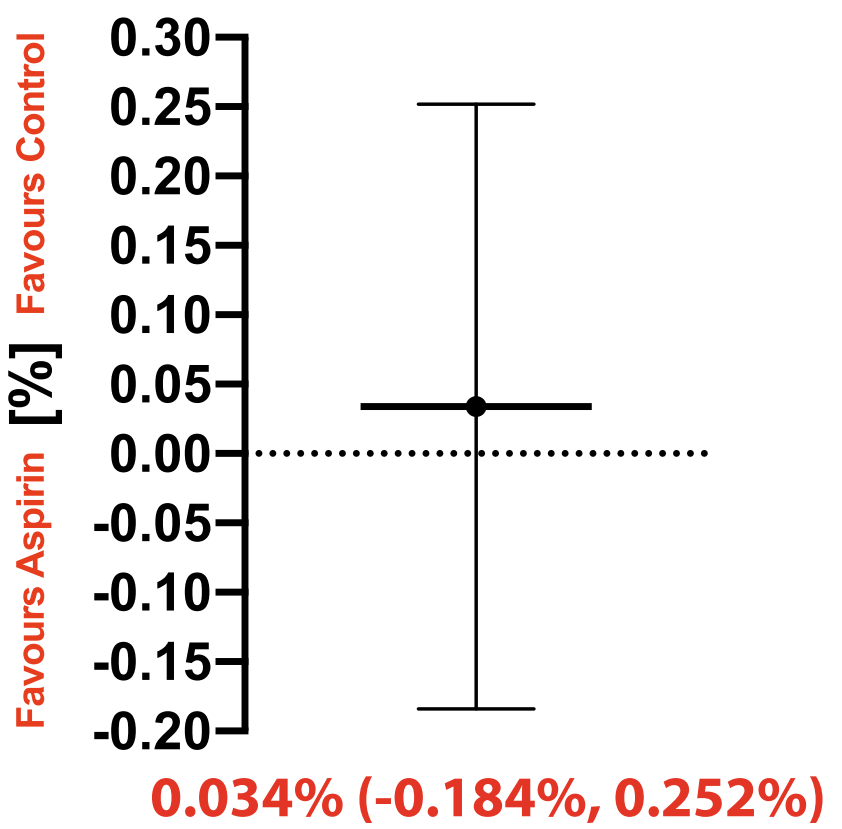

Fig. 2 Analysis of the mortality-adjusted net clinical benefit

Sex

MACE: Nine trials, including 59,337 patients, reported the incidence of MACE in men $[18,19,25,28,30,34-$ $37]$, seven trials in women $(69,164$ patients) $[18,19,29$, 34-37]. There was a sex interaction for aspirin effect: the direction of the effect of aspirin on MACE tended to be similar in men and women, but the effect size differed, and did not reach statistical significance in females. Aspirin in men was associated with a RRR of MACE of $11 \%$ (RR 0.89 ; 95\% CI, 0.83-0.95; $p=0.0008$; $I^{2}=12 \%$; Fig. 5) compared with controls. In women, aspirin did not significantly reduce the risk of MACE (RR 0.95; 95\% CI, 0.88-1.02; $p=0.16$; $I^{2}=0 \%$; Fig. 5) compared with controls.

Myocardial infarction: Three trials, including 32,295 patients, reported on MI in men [25, 28, 30], only one in

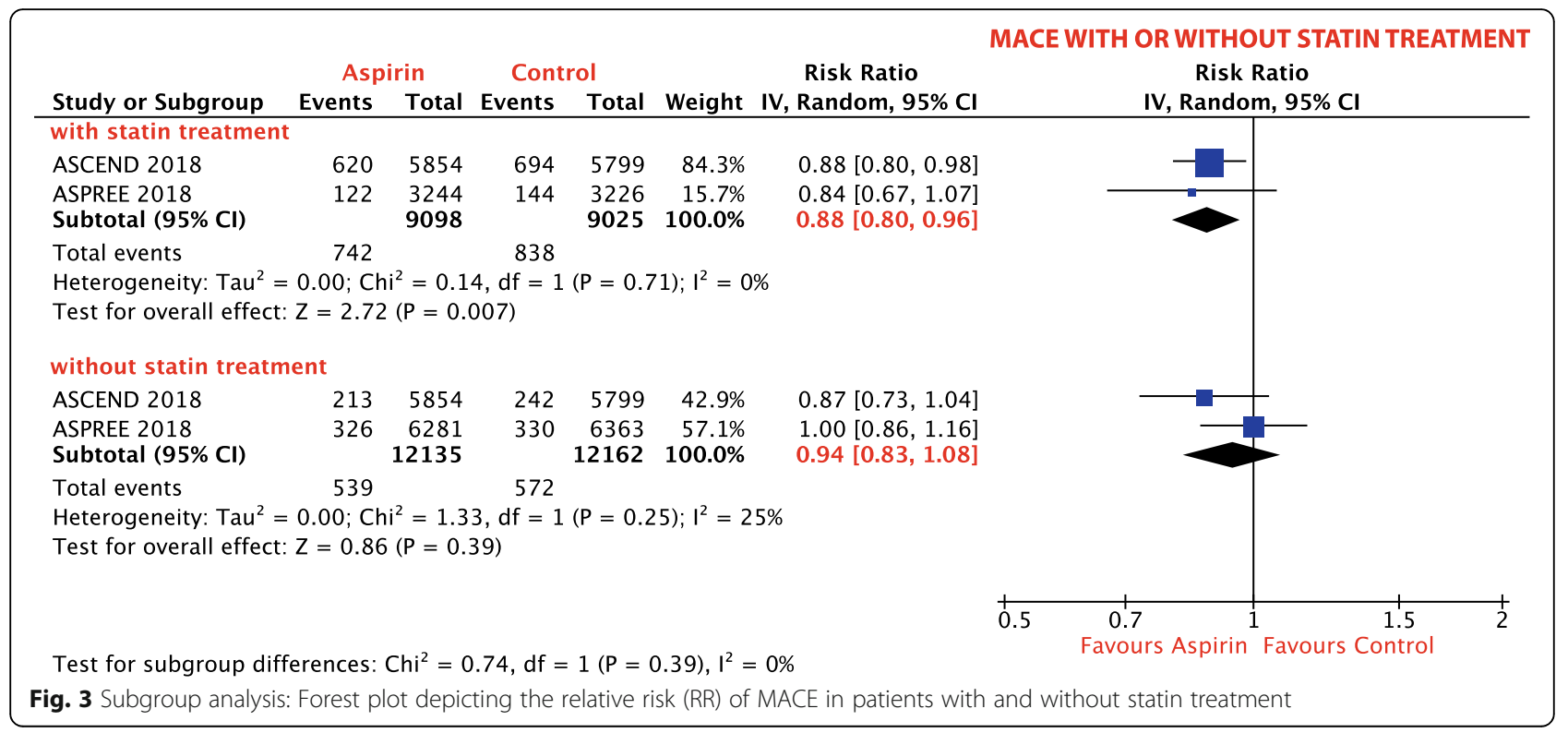




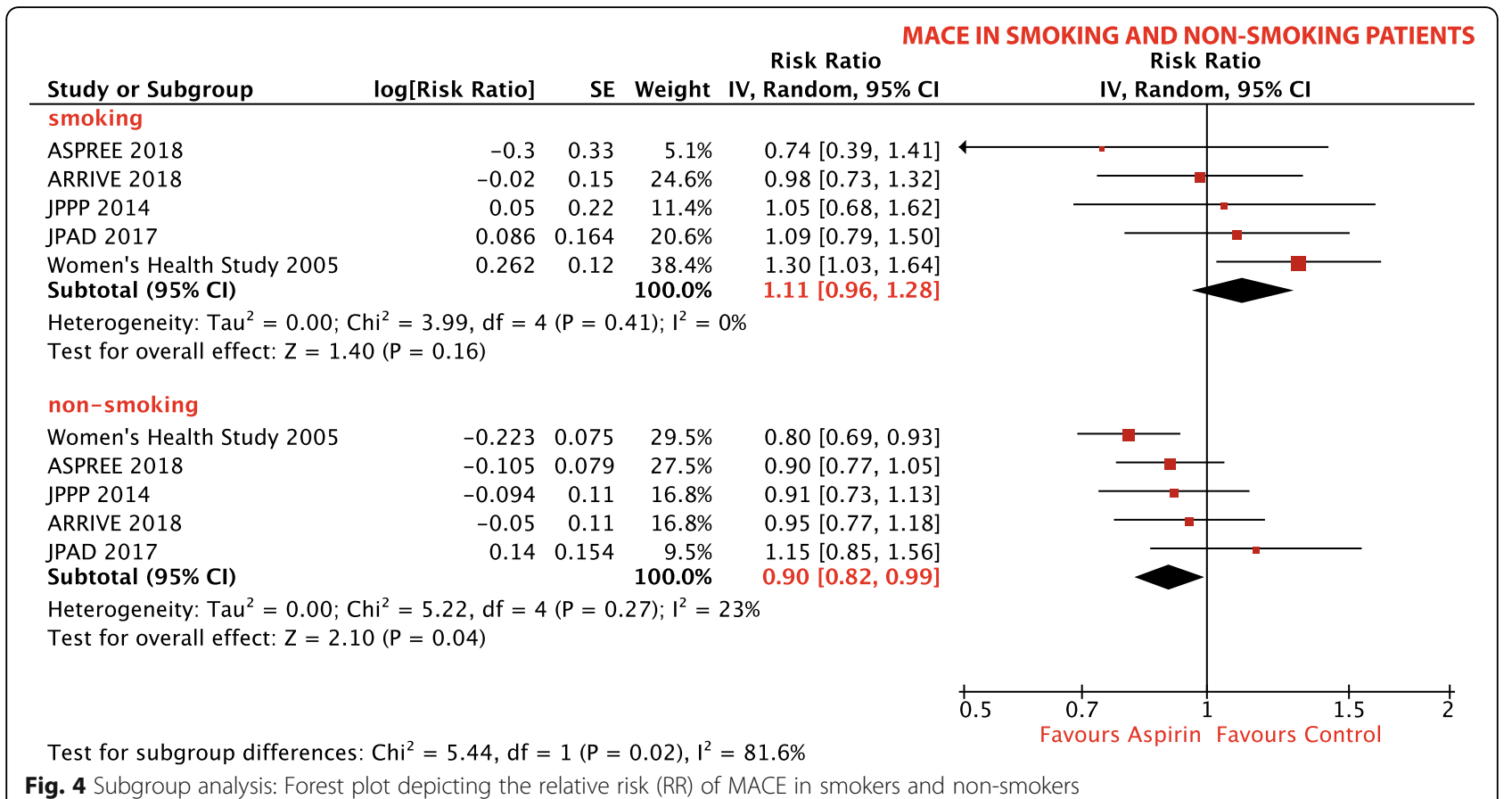

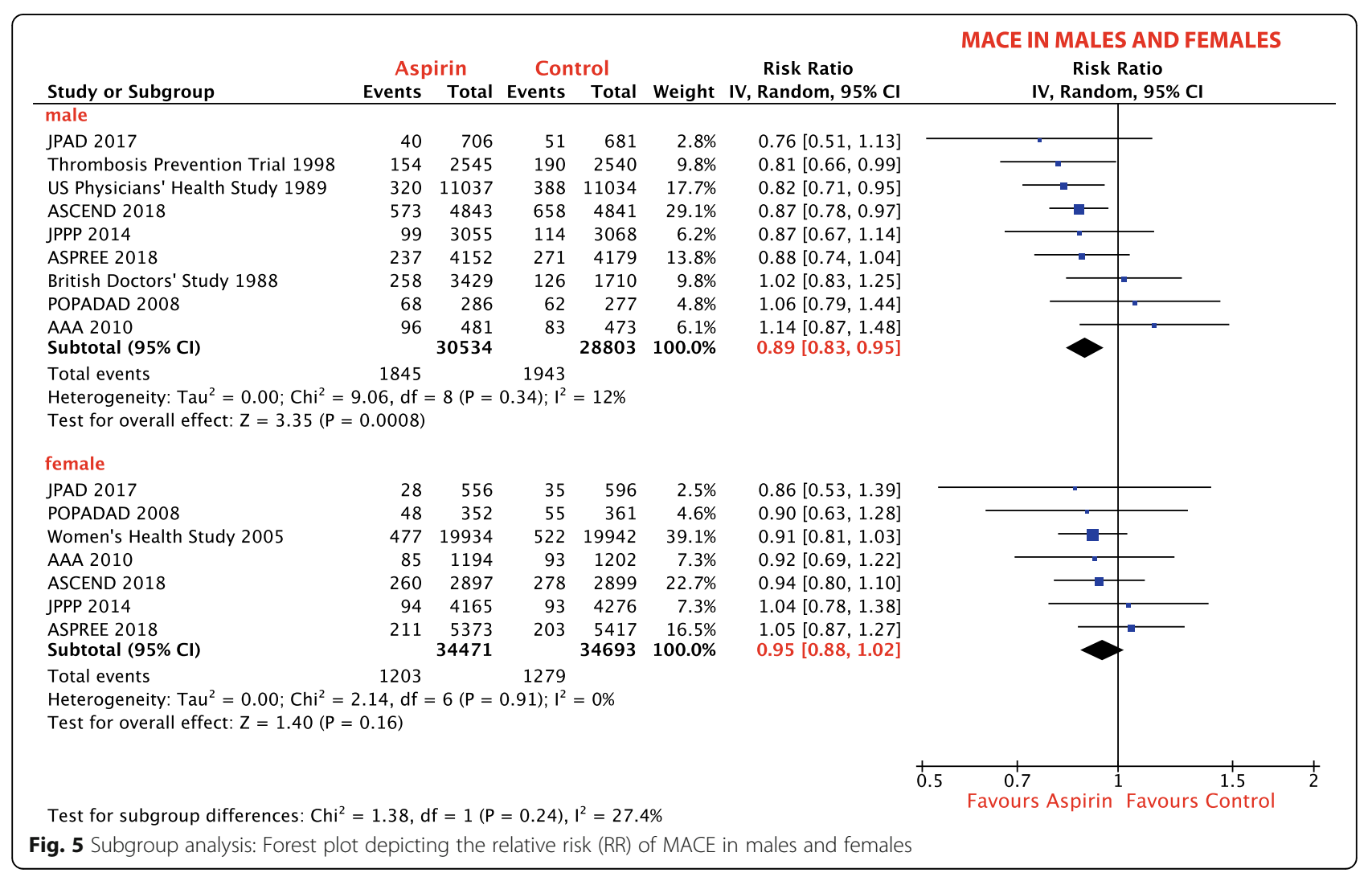


women (39,876 patients) [29]. In men and in women, aspirin did not significantly reduce the risk of MI (RR 0.76; 95\% CI, 0.57-1.01; $p=0.06 ; I^{2}=76 \%$; RR 1.03; 95\% CI, $0.84-1.25 ; p=0.26$; respectively). This is in contrast to the overall population and underlines that the sex sub-analysis for MI is underpowered.

Ischemic stroke: Three trials, including 32,295 patients, reported on IS in men [25, 28, 30], but only one trial reported these data for women (39,876 patients) [29]. Aspirin did not reduce the RR of IS in men (RR 1.02; 95\% CI, 0.72-1.44; $\left.p=0.93 ; I^{2}=55 \%\right)$. In women, however, aspirin reduced IS by $23 \%$ (RR 0.77 ; 95\% CI, $0.63-$ $0.94 ; p=0.010)$ compared to control as reported in one study.

\section{Diabetes}

MACE: Six studies, including 27,292 patients, reported on the rate of primary endpoint in patients with diabetes, showing a RRR of MACE by $9 \%$ (RR 0.91; $95 \%$ CI, $0.85-0.99 ; p=0.02 ; I^{2}=0 \%$, Fig. 6), which is consistent with the analysis of the overall population. No data for a non-diabetic subgroup were available.

Myocardial infarction: Five studies, comprising 20,865 patients, provided data for MI in diabetic patients, showing no difference between aspirin vs. control (RR 0.94; 95\% CI, 0.72-1.23; $p=0.65 ; I^{2}=53 \%$ ) [18, 29, 30, 36, 37].

Ischemic stroke: Four studies, including 20,332 patients, reported on IS in diabetic patients, showing a RRR of IS by aspirin of $24 \%$ (RR 0.76 ; 95\% CI, 0.59-0.98; $\left.p=0.03 ; I^{2}=43 \%\right)[18,29,36,37]$.

Sensitivity analyses: Sensitivity analysis assessing the date of publication showed that the direction of the effect on MACE remained unchanged. However, the magnitude of the effect tended to be greater in studies published before 2010 compared to studies published after this date (RRR $11 \%$ vs. $7 \%$, respectively).

Due to low heterogeneity $\left(I^{2}=0 \%\right)$, a fixed-effect model was calculated in addition to the random-effect model for each outcome (Additional file 1: Table S1), which confirmed the robustness of our findings.

By sequentially excluding one single study from the pooled analysis, the direction and the magnitude of the effect on MACE remained unchanged.

Sensitivity analysis assessing the length of follow-up/ length of study drug use showed that the direction of effect on MACE remained unchanged. However, the magnitude of the effect tended to be greater in studies with a shorter-term use of aspirin ( $\leq 5$ years, RRR $13 \%$ ) vs. longer-term use ( $>5$ years, RRR $8 \%$ ).

We additionally analyzed the primary endpoint of each study according to the study definition (which in some studies slightly differed from the MACE definition used in our meta-analysis). In the aspirin group, $4.3 \%$ of patients $(3601 / 82,900)$ reached the primary endpoint compared to $4.7 \%$ in the control group $(3827 / 81,325)$. Treatment with aspirin, therefore, significantly reduced the RR of the primary endpoint by $9 \%$ (RR $0.91 ; 95 \% \mathrm{CI}$, $\left.0.87-0.95 ; p<0.0001 ; I^{2}=0 \%\right)$, confirming the result of the MACE analysis.

\section{Discussion}

Our meta-analysis in over 160,000 patients without a history of CVD showed that aspirin did not reduce allcause or CV mortality but reduced the risk of MACE, $\mathrm{MI}$, and IS at the cost of an increased risk of major bleeding events. Hence, aspirin treatment was associated with a lower NNH than the NNT for the safety and efficacy outcomes: major bleeding and MACE: 1295 vs. 1908 respectively. Most importantly, our meta-analysis shows that there is a treatment interaction in three subgroups: non-smokers, male sex, and treatment with statins.

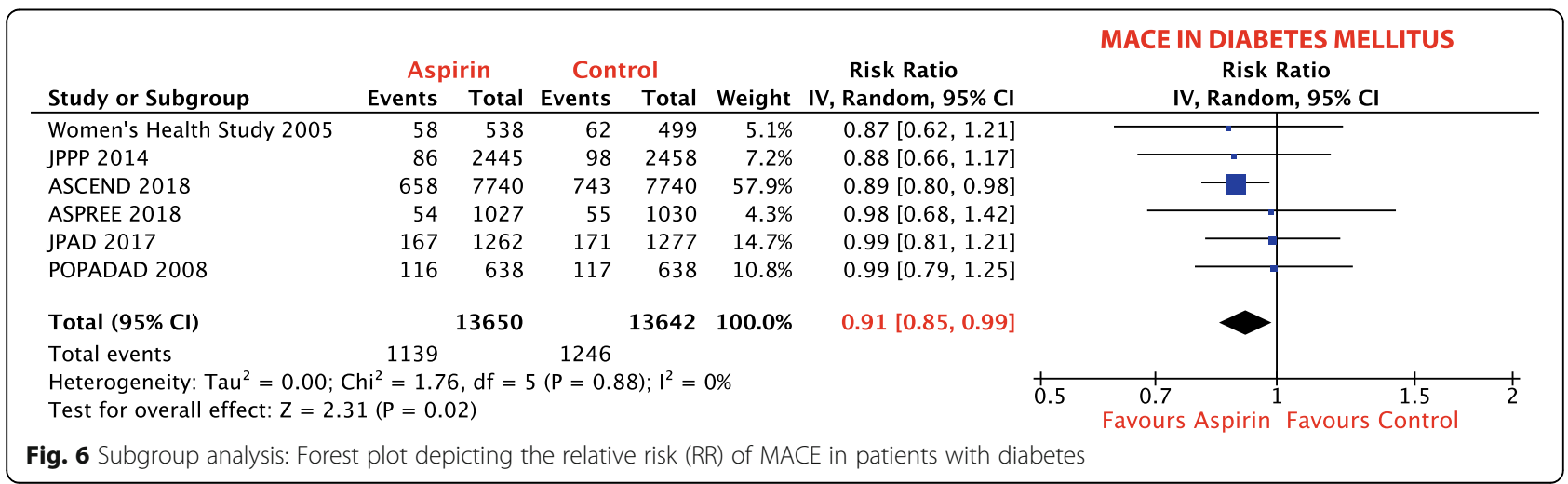


Two recently published meta-analyses have provided information about the use of aspirin in primary prevention of CVD [39, 40]. Our meta-analysis confirms previous findings and provides additional value with four distinct subgroup analyses and a mortality-adjusted net clinical benefit analysis.

One of the most important findings of our study is the net clinical benefit of aspirin, adjusted for the risk of event-associated mortality, which aims to balance the preventive impact of aspirin on risk for ischemic events such as MI and IS, versus the impact of increased risk of bleeding. The outcome of intracranial hemorrhage is generally worse than the outcome of IS or MI, with the best outcome following a GI bleeding event. Based on previous estimates [31, 32], we weighted hemorrhagic stroke threefold worse than IS. Our weighted analysis provides quantitative assessments of the net clinical benefit of aspirin among primary CVD prevention patients and confirms the result of the crude net clinical benefit estimation. Although models adjusting for eventassociated mortality are commonly used [31, 32], weighting one nonfatal event against another is very difficult, as the risks might differ between patients. Therefore, it is still unclear how to properly weight an ischemic event against a bleeding event. Some people with a high risk of having an ischemic event will prefer to take the risk of having a GI-bleed on aspirin, in order to reduce the risk of IS or MI. As there was no significant difference in mortality, intracerebral hemorrhage, or hemorrhagic stroke between aspirin and control, patient preferences should be considered.

Considering upper GI bleeding, which is the most common complication in patients under antiplatelet therapy [41-43], PPIs have been proven effective in the prevention of GI bleeding and are recommended in patients at increased risk for this bleeding [44]. On the other hand, long-term treatment with PPIs is associated with increased risk of community-acquired pneumonia (CAP) [45], bone fractures [45, 46], and enteric infections, mainly by Salmonella and Campylobacter spp. [45]. Furthermore, PPI-related hypomagnesemia is of clinical significance as it is a known cause of cardiac arrhythmias [45]. Thus, in consideration of the benefits and risks of the respective treatments, the question arises as to whether patients without bleeding risk should receive long-term treatment with PPIs concomitantly with aspirin for primary prevention.

A population of special interest is patients treated with statins. Interestingly, our subgroup analysis comprising 18,000 patients who were concomitantly treated with statins and aspirin showed a benefit in terms of MACE reduction, whereas those treated with aspirin without statins did not. Remarkably, patients treated with aspirin and statins showed the highest RRR of MACE of $12 \%$ compared to the overall population and patients with DM. A possible explanation for this interaction might be the consideration that those taking statins are at higher risk for CVD because of hyperlipidemia, and therefore might benefit more. Another possible elaboration might be a direct plaque-stabilizing effect of statins, which, in combination with platelet inhibition by aspirin, improves ischemic outcome. Notably, statins are associated with reduced platelet reactivity and improved response to aspirin [47-52]. However, it is unclear whether the improved response to aspirin under statin treatment is caused directly by statin-platelet interaction, indirectly via reduced levels of lipids $[47-49,51,52]$, or by a combination of the two. Elevated cholesterol levels have been linked to decreased aspirin-induced platelet acetylation, explaining the indirect effect of statins on platelet inhibition [53]. Two mechanisms have been identified as being involved in the direct effect of statins on platelets [54]. Administration of atorvastatin resulted in the downregulation of phospholipase A2 (PLA2) (after 24h) and NOX2 (after $2 \mathrm{~h}$ ) leading to reduced levels of $\mathrm{TxA}_{2}$ and prothrombotic platelet isoprostanes respectively [55]. Based on these findings, early and late antiplatelet effects of statins have been hypothesized [54].

Interestingly, our subgroup analysis showed aspirin use in non-smokers to reduce the risk of MACE by $10 \%$, whereas smokers did not benefit from aspirin treatment. This confirms the result of a previous meta-analysis by Seidu et al., who describe a $30 \%$ risk reduction with aspirin in non-smokers [56]. Smoking has been linked to an attenuated antiplatelet effect of aspirin in the past [57-59], and our meta-analysis suggests a possible translation of this phenomenon into clinical practice. In current smokers, a treatment switch from aspirin to the $\mathrm{P}_{12} \mathrm{Y}_{12}$ receptor inhibitor clopidogrel seems to be an interesting alternative. Smoking is a known inducer of cytochrome P450 (CYP) 1A2, an essential isoenzyme that converts clopidogrel into its active metabolite, and thus may facilitate an adequate platelet inhibition [60]. Studies have demonstrated fewer ischemic events in smokers following clopidogrel administration [61, 62]; however, in primary prevention of CVD, the overall role of clopidogrel has not yet been investigated.

It is crucial to note that our meta-analysis has shown sex differences in aspirin effects. Aspirin showed a reduction of MACE in men but not in women. In contrast, aspirin reduced the risk of stroke in women as shown in a single study, but not in men. Results from previous meta-analyses have also detected a more pronounced effect of aspirin for MACE or MI in men and for stroke in women [5, 63-65]. Although sex differences in aspirin effects are of interest, it is currently unclear how they can be used in clinical decisionmaking $[8,16,66]$. 
Another population of special interest is patients with DM. Diabetes increases the risk of CVD, and aspirin is therefore expected to have a greater preventive effect in these patients [67]. In our subgroup analysis comprising over 20,000 patients with diabetes mellitus, aspirin showed a significant 9\% RRR in MACE, which confirms the estimate in the overall population. While older guidelines have deemed the use of aspirin reasonable in certain patient populations with diabetes [66], current 2019 guidelines from the ACC/AHA do not specifically comment on the use of aspirin in diabetic patients in primary prevention of CVD [15]. The newly published ESC guidelines on diabetes, pre-diabetes, and CVD have stated aspirin may be used in patients with DM at high/ very high risk of CVD and in the absence of clear contraindications (class IIb) [68].

In the general population, the U.S. Preventive Services Task Force's guideline recommends aspirin for patients based on age and prediction tools such as the 10-year cardiovascular disease calculator [16]. Importantly, these recommendations are given with a moderate evidence level (B and C). The 2019 ACC/ AHA guidelines acknowledge the controversy of aspirin in primary prevention of CVD, but state that aspirin might be considered in selected adults aged 40 to 70 who are at higher $\mathrm{CV}$ risk but at no increased bleeding risk [15]. Additionally, two cost-utility analyses suggest a clear benefit of aspirin [69, 70]. However, the ESC guidelines on CVD prevention do not recommend the general use of aspirin for the primary prevention of cardiovascular disease [8].

\section{Limitations}

The main limitation is that some studies did not differentiate between ischemic and hemorrhagic stroke. In such cases, the total of "all strokes" was included. The primary endpoint and follow-up periods also differed between some studies; we have adjusted for this in the sensitivity analyses. Another limitation of this meta-analysis was the use of heterogeneous definitions of major bleeding. One study used the GUSTO bleeding classification [17]; most others used a prespecified composite of bleeding events such as GI bleeding and major extracranial bleeding and defined their severity by hospitalization, prolongation of hospitalization, surgery, transfusion requirement, or fatality. The severity and definition of GI bleeding events were often not further detailed.

Furthermore, some trials included in our meta-analysis $[25,27,28,30]$ were performed several decades ago. Since then, there may have been changes in medical standards, the prevalence of risk factors, and access to early diagnostic services.

\section{Conclusions}

The increased risk of major bleeding and lack of reduction of mortality might outweigh the benefits of aspirin in primary prevention of CVD in the overall population. Three patient subgroups: non-smokers, patients treated with statins, and males, had the greatest risk reduction of MACE.

\section{Additional file}

\begin{abstract}
Additional file 1: Figure S1. Workflow of studies included in the metaanalysis. Figure S2. Forest plots depicting the relative risk (RR) of the (A) Primary efficacy outcome (all-cause mortality), (B) MACE and (C) primary safety outcome (major bleeding). Figure S3. Forest plots depicting the relative risk (RR) of the (A) Primary efficacy outcome (all-cause mortality), (B) MACE and (C) primary safety outcome (major bleeding). Figure S4. Forest plots depicting the relative risk (RR) of (A) extracranial major bleeding, (B) hemorrhagic stroke, (C) gastrointestinal (Gl) bleeding and (D) intracranial hemorrhage. Figure S5. Forest plot depicting the relative risk (RR) of cancer. Figure S6. Forest plot depicting the crude net clinical benefit (NCB) analysis. Table S1. Random-effect and fixed-effect models calculated for primary, secondary and exploratory outcomes.
\end{abstract}

\section{Abbreviations}

ABI: Ankle-brachial index; ARR/l: Absolute risk reduction/increase; CAP: Community-acquired pneumonia; COX-1: Cyclooxygenase-1;

CV: Cardiovascular; CVD: Cardiovascular disease; CYP: Cytochrome P450;

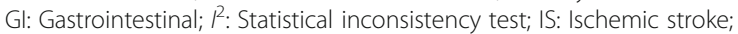
MACE: Major adverse cardiovascular event; MI: Myocardial infarction; NNT/ NNH: Number needed to treat/harm; NO: Nitric oxide; PLA2: Phospholipase A2; PRISMA: Preferred Reporting Items for Systematic Reviews and MetaAnalyses; RCT: Randomized controlled trial; RR: Relative risk; RRR/l: Relative risk reduction/increase; $\mathrm{TXA}_{2}$ : Thromboxane $\mathrm{A}_{2}$; DM: Diabetes mellitus; $95 \%$ $\mathrm{Cl}$ : $95 \%$ confidence interval

\section{Acknowledgements}

The authors would like to thank Sarah Ely for proofreading the manuscript.

\section{Authors' contributions}

GG and JMSM conceptualized the study. GG and JMSM were involved in the acquisition and interpretation of the data. GG, LP, and JMSM performed the statistical analysis. GG drafted the manuscript; all authors were substantially involved in the critical revision of the manuscript. All authors read and approved the final version of the manuscript.

Funding

GG is supported by grant SFB54-P04 from the Austrian Science Funds. The funding had no role in the study design, data collection and analysis, decision to publish, or preparation of the manuscript.

\section{Availability of data and materials}

All data was extracted from already published research and can be accessed by everyone; all publicly available data is cited.

Ethics approval and consent to participate:

Not applicable.

Consent for publication:

Not applicable.

\section{Competing interests:}

LP reports personal fees from Daiichi Sankyo Europe, personal fees from SOTIO, and personal fees from Beckman Coulter, outside the submitted work. ML reports personal fees from Astra Zeneca, personal fees from Bayer, personal fees from Boehringer Ingelheim, and personal fees from Pfizer, outside the submitted work. BJ reports grants from Bayer, during the 
conduct of the study. The other authors declare that they have no competing interests.

\section{Author details}

${ }^{1}$ Department of Clinical Pharmacology, Medical University of Vienna, Vienna, Austria. ${ }^{2}$ Department of Experimental and Clinical Pharmacology, Centre for Preclinical Research and Technology (CEPT), Medical University of Warsaw, Warsaw, Poland. ${ }^{3}$ Institute of Computer Science of Academy of Sciences of the Czech Republic, Prague, Czech Republic. "Department of Cardiology, Oslo University Hospital, Oslo, Norway. ${ }^{5} 1$ st Department of Cardiology, Poznan University of Medical Sciences, Poznan, Poland. ${ }^{6}$ Division of Cardiology, Department of Internal Medicine II, Medical University of Vienna, Währinger Gürtel 18-20, 1090 Vienna, Austria.

\section{Received: 23 May 2019 Accepted: 19 September 2019} Published online: 04 November 2019

\section{References}

1. Pruller F, Milke OL, Bis L, Fruhwald F, Scherr D, Eller P, et al. Impaired aspirinmediated platelet function inhibition in resuscitated patients with acute myocardial infarction treated with therapeutic hypothermia: a prospective, observational, non-randomized single-centre study. Ann Intensive Care. 2018;8(1):28

2. Siller-Matula JM, Delle-Karth G, Christ G, Neunteufl T, Maurer G, Huber K, et al. Dual non-responsiveness to antiplatelet treatment is a stronger predictor of cardiac adverse events than isolated non-responsiveness to clopidogrel or aspirin. Int J Cardiol. 2013;167(2):430-5.

3. Siller-Matula JM, Krumphuber J, Jilma B. Pharmacokinetic, pharmacodynamic and clinical profile of novel antiplatelet drugs targeting vascular diseases. $\mathrm{Br}$ J Pharmacol. 2010;159(3):502-17.

4. Antithrombotic TC. Collaborative meta-analysis of randomised trials of antiplatelet therapy for prevention of death, myocardial infarction, and stroke in high risk patients. BMJ. 2002;324(7329):71-86.

5. Antithrombotic Trialists C, Baigent C, Blackwell L, Collins R, Emberson J, Godwin J, et al. Aspirin in the primary and secondary prevention of vascular disease: collaborative meta-analysis of individual participant data from randomised trials. Lancet. 2009;373(9678):1849-60.

6. Berger JS, Brown DL, Becker RC. Low-dose aspirin in patients with stable cardiovascular disease: a meta-analysis. Am J Med. 2008;121(1):43-9.

7. Fihn SD, Gardin JM, Abrams J, Berra K, Blankenship JC, Dallas AP, et al. 2012 ACCF/AHA/ACP/AATS/PCNA/SCAI/STS guideline for the diagnosis and management of patients with stable ischemic heart disease: a report of the American College of Cardiology Foundation/American Heart Association task force on practice guidelines, and the American College of Physicians, American Association for Thoracic Surgery, Preventive Cardiovascular Nurses Association, Society for Cardiovascular Angiography and Interventions, and Society of Thoracic Surgeons. Circulation. 2012;126(25):e354-471.

8. Piepoli MF, Hoes AW, Agewall S, Albus C, Brotons C, Catapano AL, et al. 2016 European Guidelines on cardiovascular disease prevention in clinical practice: The Sixth Joint Task Force of the European Society of Cardiology and Other Societies on Cardiovascular Disease Prevention in Clinical Practice (constituted by representatives of 10 societies and by invited experts) Developed with the special contribution of the European Association for Cardiovascular Prevention \& Rehabilitation (EACPR). Eur Heart J. 2016;37(29):2315-81.

9. Siller-Matula JM. Hemorrhagic complications associated with aspirin: an underestimated hazard in clinical practice? JAMA. 2012;307(21):2318-20.

10. Bartolucci AA, Tendera M, Howard G. Meta-analysis of multiple primary prevention trials of cardiovascular events using aspirin. Am J Cardiol. 2011; 107(12):1796-801.

11. Guirguis-Blake JM, Evans CV, Senger CA, O'Connor EA, Whitlock EP. Aspirin for the primary prevention of cardiovascular events: a systematic evidence review for the U.S. Preventive Services Task Force. Ann Intern Med. 2016; 164(12):804-13.

12. Raju N, Sobieraj-Teague M, Hirsh J, O'Donnell M, Eikelboom J. Effect of aspirin on mortality in the primary prevention of cardiovascular disease. Am J Med. 2011;124(7):621-9.

13. Seshasai SR, Wijesuriya S, Sivakumaran R, Nethercott S, Erqou S, Sattar N, et al. Effect of aspirin on vascular and nonvascular outcomes: meta-analysis of randomized controlled trials. Arch Intern Med. 2012;172(3):209-16.
14. Berger JS, Lala A, Krantz MJ, Baker GS, Hiatt WR. Aspirin for the prevention of cardiovascular events in patients without clinical cardiovascular disease: a meta-analysis of randomized trials. Am Heart J. 2011;162(1):115-24 e2.

15. Arnett DK, Blumenthal RS, Albert MA, Buroker AB, Goldberger ZD, Hahn EJ, et al. ACC/AHA guideline on the primary prevention of cardiovascular disease. Circulation. 2019;2019:CIR0000000000000678.

16. Bibbins-Domingo K, Force USPST. Aspirin use for the primary prevention of cardiovascular disease and colorectal Cancer: U.S. Preventive Services Task Force recommendation statement. Ann Intern Med. 2016;164(12):836-45.

17. Gaziano JM, Brotons C, Coppolecchia R, Cricelli C, Darius H, Gorelick $P B$, et al. Use of aspirin to reduce risk of initial vascular events in patients at moderate risk of cardiovascular disease (ARRIVE): a randomised, double-blind, placebo-controlled trial. Lancet. 2018; 392(10152):1036-46.

18. Group ASC, Bowman L, Mafham M, Wallendszus K, Stevens W, Buck G, et al. Effects of aspirin for primary prevention in persons with diabetes mellitus. $N$ Engl J Med. 2018;379(16):1529-39.

19. McNeil JJ, Wolfe R, Woods RL, Tonkin AM, Donnan GA, Nelson MR, et al. Effect of aspirin on cardiovascular events and bleeding in the healthy elderly. N Engl J Med. 2018;379(16):1509-18.

20. Gouya G, Arrich J, Wolzt M, Huber K, Verheugt FW, Gurbel PA, et al. Antiplatelet treatment for prevention of cerebrovascular events in patients with vascular diseases: a systematic review and meta-analysis. Stroke. 2014; 45(2):492-503.

21. Navarese EP, De Luca G, Castriota F, Kozinski M, Gurbel PA, Gibson CM, et al. Low-molecular-weight heparins vs. unfractionated heparin in the setting of percutaneous coronary intervention for ST-elevation myocardial infarction: a meta-analysis. J Thromb Haemost. 2011;9(10):1902-15.

22. Siller-Matula JM, Huber K, Christ G, Schror K, Kubica J, Herkner H, et al. Impact of clopidogrel loading dose on clinical outcome in patients undergoing percutaneous coronary intervention: a systematic review and meta-analysis. Heart. 2011;97(2):98-105.

23. Siller-Matula JM, Jilma B, Schror K, Christ G, Huber K. Effect of proton pump inhibitors on clinical outcome in patients treated with clopidogrel: a systematic review and meta-analysis. J Thromb Haemost. 2010;8(12):2624-41.

24. Siller-Matula JM, Petre A, Delle-Karth G, Huber K, Ay C, Lordkipanidze $M$, et al. Impact of preoperative use of $P 2 Y 12$ receptor inhibitors on clinical outcomes in cardiac and non-cardiac surgery: a systematic review and meta-analysis. Eur Heart J Acute Cardiovasc Care. 2017; 6(8):753-70.

25. The Medical Research Council's General Practice Research Framework. Thrombosis prevention trial: randomised trial of low-intensity oral anticoagulation with warfarin and low-dose aspirin in the primary prevention of ischaemic heart disease in men at increased risk. Lancet. 1998;351(9098):233-41.

26. de Gaetano G, Collaborative Group of the Primary Prevention P. Low-dose aspirin and vitamin $\mathrm{E}$ in people at cardiovascular risk: a randomised trial in general practice. Collaborative Group of the Primary Prevention Project. Lancet. 2001;357(9250):89-95.

27. Hansson L, Zanchetti A, Carruthers SG, Dahlof B, Elmfeldt D, Julius S, et al. Effects of intensive blood-pressure lowering and low-dose aspirin in patients with hypertension: principal results of the Hypertension Optimal Treatment (HOT) randomised trial. HOT Study Group Lancet. 1998;351(9118):1755-62.

28. Peto R, Gray R, Collins R, Wheatley K, Hennekens C, Jamrozik K, et al. Randomised trial of prophylactic daily aspirin in British male doctors. Br Med J (Clin Res Ed). 1988;296(6618):313-6.

29. Ridker PM, Cook NR, Lee IM, Gordon D, Gaziano JM, Manson JE, et al. A randomized trial of low-dose aspirin in the primary prevention of cardiovascular disease in women. N Engl J Med. 2005;352(13):1293-304.

30. Steering Committee of the Physicians' Health Study Research G. Final report on the aspirin component of the ongoing Physicians' Health Study. N Engl J Med. 1989;321(3):129-35.

31. Eikelboom JW, Connolly SJ, Hart RG, Wallentin L, Reilly P, Oldgren J, et al. Balancing the benefits and risks of 2 doses of dabigatran compared with warfarin in atrial fibrillation. J Am Coll Cardiol. 2013;62(10):900-8.

32. Patti G, Lucerna M, Pecen L, Siller-Matula JM, Cavallari I, Kirchhof $P$, et al. Thromboembolic risk, bleeding outcomes and effect of different antithrombotic strategies in very elderly patients with atrial fibrillation: a sub-analysis from the PREFER in AF (PREvention of Thromboembolic 
Events-European Registry in Atrial Fibrillation). J Am Heart Assoc. 2017;6(7): e005657. https://doi.org/10.1161/JAHA.117.005657.

33. Aspirin effects on mortality and morbidity in patients with diabetes mellitus. Early Treatment Diabetic Retinopathy Study report 14. ETDRS Investigators. JAMA. 1992;268(10):1292-300.

34. Fowkes FG, Price JF, Stewart MC, Butcher I, Leng GC, Pell AC, et al. Aspirin for prevention of cardiovascular events in a general population screened for a low ankle brachial index: a randomized controlled trial. JAMA. 2010;303(9):841-8.

35. Ikeda Y, Shimada K, Teramoto T, Uchiyama S, Yamazaki T, Oikawa S, et al. Low-dose aspirin for primary prevention of cardiovascular events in Japanese patients 60 years or older with atherosclerotic risk factors: a randomized clinical trial. JAMA. 2014;312(23):2510-20.

36. Saito Y, Okada S, Ogawa H, Soejima H, Sakuma M, Nakayama M, et al. Lowdose aspirin for primary prevention of cardiovascular events in patients with type 2 diabetes mellitus: 10-year follow-up of a randomized controlled trial. Circulation. 2017;135(7):659-70.

37. Belch J, MacCuish A, Campbell I, Cobbe S, Taylor R, Prescott R, et al. The prevention of progression of arterial disease and diabetes (POPADAD) trial: factorial randomised placebo controlled trial of aspirin and antioxidants in patients with diabetes and asymptomatic peripheral arterial disease. BMJ. 2008;337:a1840.

38. Ogawa H, Nakayama M, Morimoto T, Uemura S, Kanauchi M, Doi N, et al. Low-dose aspirin for primary prevention of atherosclerotic events in patients with type 2 diabetes: a randomized controlled trial. JAMA. 2008; 300(18):2134-41.

39. Mahmoud AN, Gad MM, Elgendy AY, Elgendy IY, Bavry AA. Efficacy and safety of aspirin for primary prevention of cardiovascular events: a meta-analysis and trial sequential analysis of randomized controlled trials. Eur Heart J. 2019:40(7):607-17.

40. Zheng SL, Roddick AJ. Association of aspirin use for primary prevention with cardiovascular events and bleeding events: a systematic review and meta-analysis. JAMA. 2019;321(3):277-87.

41. Derry S, Loke YK. Risk of gastrointestinal haemorrhage with long term use of aspirin: meta-analysis. BMJ. 2000;321(7270):1183-7.

42. Lanas A, Carrera-Lasfuentes P, Arguedas Y, Garcia S, Bujanda L, Calvet X, et al. Risk of upper and lower gastrointestinal bleeding in patients taking nonsteroidal anti-inflammatory drugs, antiplatelet agents, or anticoagulants. Clin Gastroenterol Hepatol. 2015;13(5):906-12 e2.

43. Lanas A, Wu P, Medin J, Mills EJ. Low doses of acetylsalicylic acid increase risk of gastrointestinal bleeding in a meta-analysis. Clin Gastroenterol Hepatol. 2011:9(9):762-8 e6.

44. Siller-Matula JM, Delle-Karth G. Addition of omeprazole to dual antiplatelet therapy with clopidogrel plus aspirin lowers the risk of upper gastrointestinal bleeding. Evid Based Med. 2011;16(5):144-5.

45. Malfertheiner P, Kandulski A, Venerito M. Proton-pump inhibitors: understanding the complications and risks. Nat Rev Gastroenterol Hepatol. 2017;14(12):697-710

46. Islam MM, Poly TN, Walther BA, Dubey NK, Anggraini Ningrum DN, Shabbir $S A$, et al. Adverse outcomes of long-term use of proton pump inhibitors: a systematic review and meta-analysis. Eur J Gastroenterol Hepatol. 2018; 30(12):1395-405.

47. Postula M, Rosiak M, Kaplon-Cieslicka A, Kondracka A, Trzepla E, Filipiak KJ, et al. Do statins influence platelet reactivity on acetylsalicylic acid therapy in patients with type 2 diabetes? Cardiol J. 2012;19(5):494-500

48. Pawelczyk M, Chmielewski H, Kaczorowska B, Przybyla M, Baj Z. The influence of statin therapy on platelet activity markers in hyperlipidemic patients after ischemic stroke. Arch Med Sci. 2015;11(1):115-21.

49. Barale C, Frascaroli C, Senkeev R, Cavalot F, Russo I. Simvastatin effects on inflammation and platelet activation markers in hypercholesterolemia. Biomed Res Int. 2018;2018:6508709.

50. Godino C, Pavon AG, Mangieri A, Salerno A, Cera M, Monello A, et al. Platelet reactivity in response to loading dose of atorvastatin or rosuvastatin in patients with stable coronary disease before percutaneous coronary intervention: the STATIPLAT randomized study. Clin Cardiol. 2017;40(8):605-11.

51. Toso A, De Servi S, Leoncini M, Angiolillo DJ, Calabro P, Piscione F, et al. Effects of statin therapy on platelet reactivity after percutaneous coronary revascularization in patients with acute coronary syndrome. J Thromb Thrombolysis. 2017;44(3):355-61.
52. Verdoia M, Pergolini P, Rolla R, Nardin M, Schaffer A, Barbieri L, et al. Impact of high-dose statins on vitamin $\mathrm{D}$ levels and platelet function in patients with coronary artery disease. Thromb Res. 2017;150:90-5.

53. Boncler M, Gresner P, Nocun M, Rywaniak J, Dolnik M, Rysz J, et al. Elevated cholesterol reduces acetylsalicylic acid-mediated platelet acetylation. Biochim Biophys Acta. 2007;1770(12):1651-9.

54. Violi F, Calvieri C, Ferro D, Pignatelli P. Statins as antithrombotic drugs. Circulation. 2013;127(2):251-7.

55. Pignatelli P, Carnevale R, Pastori D, Cangemi R, Napoleone L, Bartimoccia S, et al. Immediate antioxidant and antiplatelet effect of atorvastatin via inhibition of Nox2. Circulation. 2012;126(1):92-103.

56. Seidu S, Kunutsor SK, Sesso HD, Gaziano JM, Buring JE, Roncaglioni MC, et al. Aspirin has potential benefits for primary prevention of cardiovascular outcomes in diabetes: updated literature-based and individual participant data meta-analyses of randomized controlled trials. Cardiovasc Diabetol. 2019;18(1):70.

57. Larsen SB, Grove EL, Neergaard-Petersen S, Wurtz M, Hvas AM, Kristensen SD. Determinants of reduced antiplatelet effect of aspirin in patients with stable coronary artery disease. PLoS One. 2015;10(5):e0126767.

58. Li WJ, Zhang HY, Miao CL, Tang RB, Du X, Shi JH, et al. Cigarette smoking inhibits the anti-platelet activity of aspirin in patients with coronary heart disease. Chin Med J. 2011;124(10):1569-72.

59. Ikonomidis I, Lekakis J, Vamvakou G, Andreotti F, Nihoyannopoulos P. Cigarette smoking is associated with increased circulating proinflammatory and procoagulant markers in patients with chronic coronary artery disease: effects of aspirin treatment. Am Heart J. 2005;149(5):832-9.

60. Bliden KP, Dichiara J, Lawal L, Singla A, Antonino MJ, Baker BA, et al. The association of cigarette smoking with enhanced platelet inhibition by clopidogrel. J Am Coll Cardiol. 2008;52(7):531-3.

61. Desai NR, Mega JL, Jiang S, Cannon CP, Sabatine MS. Interaction between cigarette smoking and clinical benefit of clopidogrel. J Am Coll Cardiol. 2009;53(15):1273-8.

62. Berger JS, Bhatt DL, Steinhubl SR, Shao M, Steg PG, Montalescot G, et al. Smoking, clopidogrel, and mortality in patients with established cardiovascular disease. Circulation. 2009;120(23):2337-44.

63. Berger JS, Roncaglioni MC, Avanzini F, Pangrazzi I, Tognoni G, Brown DL. Aspirin for the primary prevention of cardiovascular events in women and men: a sex-specific meta-analysis of randomized controlled trials. JAMA. 2006;295(3):306-13.

64. De Berardis G, Sacco M, Strippoli GF, Pellegrini F, Graziano G, Tognoni G, et al. Aspirin for primary prevention of cardiovascular events in people with diabetes: meta-analysis of randomised controlled trials. BMJ. 2009;339:b4531.

65. Kunutsor SK, Seidu S, Khunti K. Aspirin for primary prevention of cardiovascular and all-cause mortality events in diabetes: updated metaanalysis of randomized controlled trials. Diabet Med. 2017;34(3):316-27.

66. Fox CS, Golden SH, Anderson C, Bray GA, Burke LE, de Boer IH, et al. Update on prevention of cardiovascular disease in adults with type 2 diabetes mellitus in light of recent evidence: a scientific statement from the American Heart Association and the American Diabetes Association. Diabetes Care. 2015;38(9):1777-803.

67. Pignone $\mathrm{M}$, Williams CD. Aspirin for primary prevention of cardiovascular disease in diabetes mellitus. Nat Rev Endocrinol. 2010;6(11):619-28.

68. Cosentino F, Grant PJ, Aboyans V, Bailey CJ, Ceriello A, Delgado V, et al. 2019 ESC Guidelines on diabetes, pre-diabetes, and cardiovascular diseases developed in collaboration with the EASD. Eur Heart J. 2019:ehz486. https:// doi.org/10.1093/eurhearti/ehz486.

69. Pignone M, Earnshaw S, Pletcher MJ, Tice JA. Aspirin for the primary prevention of cardiovascular disease in women: a cost-utility analysis. Arch Intern Med. 2007;167(3):290-5.

70. Pignone M, Earnshaw S, Tice JA, Pletcher MJ. Aspirin, statins, or both drugs for the primary prevention of coronary heart disease events in men: a costutility analysis. Ann Intern Med. 2006;144(5):326-36.

\section{Publisher's Note}

Springer Nature remains neutral with regard to jurisdictional claims in published maps and institutional affiliations. 